\title{
Follow-Up Study of Susceptibility Loci for Alzheimer's Disease and Onset Age Identified by Genome-Wide Association
}

\author{
Karolien Bettens ${ }^{\mathrm{a}, \mathrm{b}, \mathrm{d}}$, Nathalie Brouwers ${ }^{\mathrm{a}, \mathrm{b}, \mathrm{d}}$, Helen Van Miegroet ${ }^{\mathrm{a}, \mathrm{b}, \mathrm{d}}$, Ana Gil ${ }^{\mathrm{a}, \mathrm{b}, \mathrm{d}}$, \\ Sebastiaan Engelborghs ${ }^{\mathrm{c}, \mathrm{d}, \mathrm{e}}$, Peter P. De Deyn ${ }^{\mathrm{c}, \mathrm{d}, \mathrm{e}}$, Rik Vandenberghe ${ }^{\mathrm{f}}$, \\ Christine Van Broeckhoven ${ }^{\mathrm{a}, \mathrm{b}, \mathrm{d}, *}$ and Kristel Sleegers ${ }^{\mathrm{a}, \mathrm{b}, \mathrm{d}}$ \\ ${ }^{a}$ Neurodegenerative Brain Diseases Group, Department of Molecular Genetics, VIB, Antwerpen, Belgium \\ ${ }^{\mathrm{b}}$ Laboratory of Neurogenetics, Institute Born-Bunge, Antwerpen, Belgium \\ ${ }^{\mathrm{c}}$ Laboratory of Neurochemistry and Behavior, Institute Born-Bunge, Antwerpen, Belgium \\ ${ }^{\mathrm{d}}$ University of Antwerp, Antwerpen, Belgium \\ ${ }^{\mathrm{e}}$ Memory Clinic and Division of Neurology, ZNA Middelheim, Antwerpen, Belgium \\ ${ }_{\mathrm{f}}^{\mathrm{f}}$ Department of Neurology, University Hospitals Leuven and University of Leuven (KUL), Leuven, Belgium
}

Handling Associate Editor: Eliecer Coto

Accepted 9 October 2009

\begin{abstract}
Replication of genetic association findings in independent studies represents an important validation tool in the search for susceptibility genes for complex diseases such as Alzheimer's disease (AD). In a well-characterized memory-clinic based study comprising 1078 unrelated $\mathrm{AD}$ patients and 652 control individuals, we set out to replicate previously reported genome-wide association of four novel risk SNPs with AD and onset age, with first stage p-values ranging from 0.001 to 0.000004 . We obtained evidence for association between rs179943, an intronic SNP in ATXN1 at 6p22.3, and affection status $(\mathrm{OR}=0.63(95 \% \mathrm{CI}=$ 0.44-0.90; nominal $p=0.01)$ ). Overall, our data provided independent support for association of at least one chromosomal locus with $\mathrm{AD}$ and warranted a more in-depth investigation of these regions for possible underlying functional variants.
\end{abstract}

Keywords: Alzheimer dementia, genome-wide association, onset age, replication

\section{INTRODUCTION}

It has long been recognized that Alzheimer's disease (AD) is a heritable disorder. Whereas a Mendelian, autosomal dominant pattern of inheritance is only present in a minority of patients, twin studies of non-autosomal

*Correspondence to: Prof. Dr. Christine Van Broeckhoven Ph.D., D.Sc., VIB and University of Antwerp - CDE, Neurodegenerative Brain Diseases Group, Department of Molecular Genetics, Parking P4, Building V, Room 0.10, Universiteitsplein 1, B-2610 Antwerpen, Belgium. Tel.: +32 3265 1001; Fax: +32 3265 1012; E-mail: christine.vanbroeckhoven@molgen.vib-ua.be. dominant AD suggested a heritability of $60-80 \%$ [4]. The unraveling of the genetic etiology of the complex form of $\mathrm{AD}$ has been the focus of intense investigation over the past decades. After the promising identification of the $A P O E \varepsilon 4$ allele as a strong genetic risk factor for $\mathrm{AD}$, however, advances have been modest (see AlzGene, http://www.alzgene.org/). In genomewide association studies (GWA) using high density arrays of single nucleotide polymorphisms (SNPs), the APOE locus invariably gave the most significant association with AD (http://www.genome.gov/gwastudies/) [1]. Nevertheless, less significant associations were also observed and might pinpoint to genuine molecular mechanisms 
underlying the disease, provided that they are not false positive signals. Therefore, replication in independent studies remains a critical step in determining which association signals are real and should be followed up in more detail.

In a recent family-based GWA, four SNPs (rs11159647, rs179943, rs3826656, and rs2049161 on chromosome $14,6,19$, and 18 respectively) in addition to $A P O E \varepsilon 4$ reached genome-wide significance following a weighted Bonferroni approach [2] in a multivariate analysis of affection status and onset age ( $\mathrm{p}$-values ranging from 0.001 to 0.000004 ) [3]. Follow up of these association signals in additional collections of family-based samples largely substantiated these findings, but support from two sets of publicly available populationbased data [5,6] remained limited. In these two studies, genotype data were available for three of the four SNPs, and statistical analyses revealed only nominally significant associations (based on one-tailed p-values) for two SNPs with $\mathrm{AD}$, each in one study population. Moreover, association with onset age could not be determined [3]. Here, we attempted to replicate the association with these four putative risk loci with both AD and onset age in a well-characterized memory-clinic based study of $\mathrm{AD}$, comprising in total 1730 unrelated $\mathrm{AD}$ patients and control individuals.

\section{MATERIALS AND METHODS}

\section{Study population}

This study was approved by the medical ethical committees of the Hospital Network Antwerp (ZNA), the University of Antwerp, and the University Hospitals of Leuven, Belgium. After informed consent, blood samples of patients and control individuals were collected for genetic studies.

The patient group consisted of 1078 AD patients (mean age of onset $=74.3 \pm 8.6$ years, $\%$ females $=66.4$ ), of which the majority was ascertained at the memory clinic of the ZNA Middelheim, Antwerpen, Belgium (SE, PPDD) in the frame of a large prospective study of neurodegenerative and vascular dementia in Flanders, the Dutch-speaking region of Belgium [7,8]. Another subset of patients $(n=47)$ were derived from a prospective study on the molecular genetics of cognitive impairment which was initiated in October 2006, in collaboration with the memory clinic of the University Hospitals of Leuven (UHL), Belgium (RV). Briefly, patients of Belgian ancestry who visited the memory clinic of the University Hospitals Leuven, and fulfilled international NINCDS/ADRDA criteria for probable $\mathrm{AD}$ [9], were asked to participate.

Upon written informed consent of the patient and a legal representative, a dedicated research nurse collected genealogical information (for determination of Belgian ancestry and family history of disease) as well as blood from patients, their spouse, and/or offspring for DNA extraction and storage of lymphoblasts, serum, and plasma. For each patient, detailed medical information and follow-up was available, including Mini-Mental State Examination (MMSE) [10] and neuroimaging (brain computerized tomography (CT), magnetic resonance imaging (MRI), single photon emission computed tomography, fluorodeoxyglucose positron emission tomography (PET), and/or amyloid imaging). Mutation screening of $A \beta P P, P S E N 1$, $P S E N 2, M A P T, G R N$, and PRNP in the patient group of the memory clinic of the ZNA Middelheim revealed 8 PSEN1 mutations, 1 A $\beta P P$ mutation, and 2 PSEN2 mutations (Brouwers et al, unpublished data). No pathogenic mutations were detected in the patient group of the memory clinic of the University Hospitals of Leuven. Both patient groups shared the same ethnicity.

Most patients met the NINCDS/ADRDA criteria of probable $\mathrm{AD}(n=880)$, whereas a small number of patients were diagnosed with possible $\mathrm{AD}(n=80)$. Autopsy established a pathological diagnosis of definite $\mathrm{AD}$ in 82 patients. Based upon the occurrence of at least one first-degree relative suffering from dementia, the disease was considered familial in $21 \%$ of the patients. For $89 \%$ of the patients, a reliable estimate of onset age was available, determined by the neurologist on the basis of a caregiver interview.

The control group ( $n=652$, mean age at inclusion $=62.7 \pm 15.7$ years, $\%$ females $=58.4$ ) consisted of healthy individuals, without neurological or psychiatric antecedents or with neurological complaints without memory complaints or organic disease involving the central nervous system. Individuals with a positive family history for dementia or an MMSE $\leqslant 24$ were omitted from the study. Population stratification was excluded as previously described [11].

\section{Genotyping}

Genomic DNA was extracted from peripheral blood lymphocytes and stored at a minimum concentration of $50 \mathrm{ng} / \mu \mathrm{l}$. PCR and extension primers for SNPs rs11159647, rs179943, rs3826656, and rs2049161 [3] 
were designed using Assay Design 3.1 Software (Sequenom, Inc., Hamburg, Germany).

A total of $20 \mathrm{ng}$ of genomic DNA was PCR amplified. Genotyping was performed by Sequenom MassArray ${ }^{\circledR}$ assay (Sequenom, Inc., Hamburg, Germany), followed by Matrix-Assisted Laser Desorption/Ionisation Time-Of-Flight (MALDI-TOF) mass spectrometry. Genotypes were scored both automatically (MassArray Typer version 4.0) as well as by two researchers (blinded to disease outcome). A mean genotyping success rate of $99.6 \%$ was obtained for AD patients (range $=99.4-99.9$ ) and $98.5 \%$ for control individuals (range $=97.6-99.1$ ). Interplate controls showed $100 \%$ concordance for all 4 SNPs.

\section{Statistical analyses}

The population of 1078 patients and 652 control individuals allow the study to achieve $95 \%$ power to detect a common variant with modest risk (MAF $=0.2$ and OR of 1.5) (Genetic Power Calculator) [12]. SNP genotype frequencies did not deviate from Hardy-Weinberg equilibrium in the overall group, as determined using the HWE program version 1.20 [13]. Considering the control group separately, genotypes of rs2049161 deviated from Hardy-Weinberg equilibrium $(\chi=6.36 ; p=$ $0.001)$. Differences in allele and genotype frequencies between $\mathrm{AD}$ patients and control individuals were tested using $\chi^{2}$ statistics. Odds ratios (OR) (calculated relative to the common genotype) with $95 \%$ confidence intervals were corrected for gender, $A P O E \varepsilon 4$ genotype (presence of one or two $A P O E \varepsilon 4$ alleles versus the absence of $A P O E \varepsilon 4$ alleles), and age of onset (age at inclusion for control individuals) using a binary logistic regression model.

The effect of SNP genotypes on onset age in patients was assessed using Cox Proportional Hazard Regression, adjusted for gender and $A P O E \varepsilon 4$ genotype. Patients for whom onset age was undetermined (11\%) were not included in the analyses, resulting in a patient group of approximately 960 individuals for the SNPs under study. All statistical analyses were performed using SPSS 14.0 for Windows (SPSS, Inc., Chicago, IL). A Bonferroni corrected p-value of 0.05 (based on the number of SNPs analyzed) was considered significant.

\section{RESULTS}

At least one SNP, rs179943 at 6p22.3, was associated with affection status in our sample (Table 1). A slight decrease in frequency of heterozygous carriers in patients versus control individuals was observed for rs 179943; heterozygous carriers had an odds ratio of $0.63(95 \% \mathrm{CI}=0.44-0.90$, Bonferroni corrected $p=$ $0.04)$ to have $\mathrm{AD}$ compared to those homozygous for the major allele (C-allele), after adjustment for age, gender, and $A P O E \varepsilon 4$. A comparable trend could be observed for homozygous carriers of the minor T-allele $(\mathrm{OR}=0.51,95 \% \mathrm{CI}=0.08-3.28)$; this difference, however, is not significant as sample sizes for these groups are probably too small to achieve accurate estimates. In line with the genotypic data, the allelic association analysis showed a decreased risk for carriers of the T-allele ( $\mathrm{OR}=0.64,95 \% \mathrm{CI}=0.46-0.89$, Bonferroni corrected $p=0.04$ ).

Although rs2049161 at 18p11.31 deviated from HWE equilibrium in control individuals, individuals homozygous for the minor allele (C-allele) showed nominally significant association with an odds ratio of 2.83 (95\% CI $=1.06-7.54$, nominal $p=0.038$ ) compared to homozygous carriers of the common allele (A-allele), suggesting that the $\mathrm{C}$-allele is the risk allele, but this did not remain significant after Bonferroni correction. Only a trend was observed for carriers of the C-allele $(\mathrm{OR}=1.25,95 \% \mathrm{CI}=0.99-1.58$, $p=0.06)$. Rs179943 and rs2049161 together explain approximately $0.8 \%$ of the variance of the trait ( $p=$ $0.016)$.

Using onset age as trait characteristic in the patient group, rs2049161 (at 18p11.31) was the only SNP showing a trend toward association after adjustment for gender and $A P O E \varepsilon 4$ state, with both heterozygous $\mathrm{CA}$ carriers and carriers of the $\mathrm{C}$-allele having an hazard ratio of 1.18 (CA genotype; $95 \% \mathrm{CI}=1.03-1.36$, Bonferroni corrected $p=0.08$; C allele; $95 \% \mathrm{CI}=1.05-1.33$, Bonferroni corrected $p=0.02$ ). Homozygous carriers of the risk allele (C-allele) had a decreased onset age of 2.6 years (mean onset age $71.8 \pm 8.6$ years) compared to homozygous carriers of the wt allele (A-allele; mean onset age $74.5 \pm 8.9$ years). Marker rs 11159647 showed a trend towards association with onset age; homozygous carriers of the minor allele (A-allele) have a reduced hazard $(\mathrm{HR}=0.84,95 \% \mathrm{CI}=0.70-1.01$, nominal $p=0.056$ ) compared to homozygous carriers of the major allele (G-allele) (Table 2). This was further confirmed by a reduced hazard for carriers of the A-allele $(\mathrm{HR}=0.92,95 \% \mathrm{CI}=0.84-1.00$, nominal $p=0.05)$, but these results did not remain significant after Bonferroni correction. 


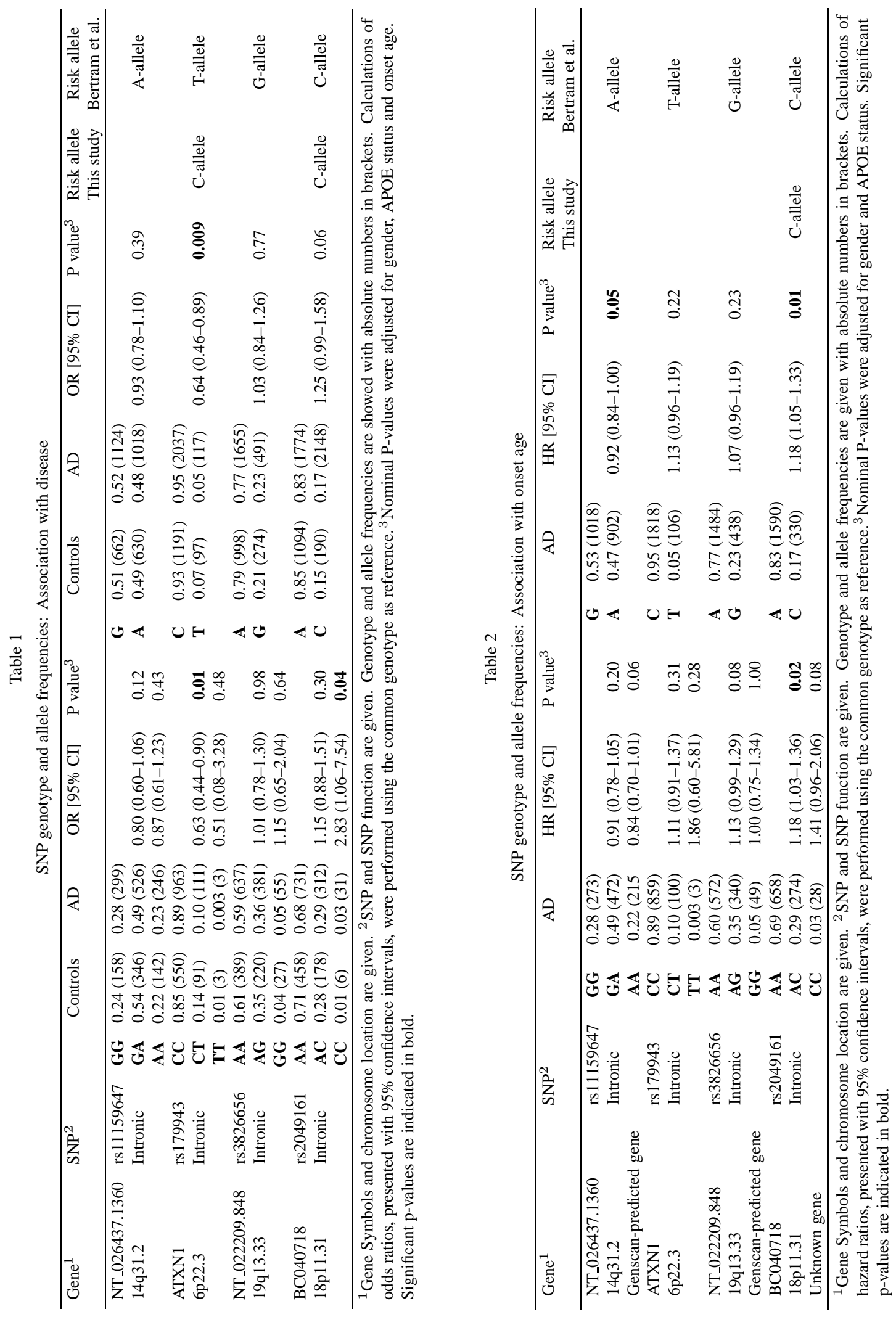




\section{DISCUSSION}

Using a large Belgian memory-clinic based sample, we attempted to replicate the association with four SNPs and AD susceptibility and onset age, as reported in a recent GWA analysis [3]. This latter study was the first to employ a large collection of family-based samples instead of population-based samples [3], an approach that has the potential of minimizing the number of false positive as well as false negative results because of its robustness to spurious effects of population substructure and less punitive multiple testing correction because of a weighted Bonferroni approach [2,14].

We identified a significant association for at least one SNP (rs179943) in our population. Evidence of association was strongest for rs179943, located in an intron of ATXN1 on chromosome 6p22.3, and surviving Bonferroni correction for the number of SNPs investigated in our study. Compared to the original report, however, in which the T-allele was associated with both affection status and onset age as a multivariate phenotype, or with affection status only, we found association with the opposite allele (C-allele). Noteworthy, this $\mathrm{C}$-allele was also overrepresented in AD patients of the publicly available TGEN and GSK datasets [5,6], but in these samples it did not reach statistical significance [3]. The ataxin-1 protein, encoded by the ATXN1 gene (MIM\#601556), is present in various brain regions and non-neuronal tissues. Elongation of the CAG trinucleotide repeat in ATXN1 results in spinocerebellar ataxia (SCA1), in which degeneration of the cerebellum, brainstem, and spinal cord causes the clinical features [15].

A second SNP, rs2049161, an intronic SNP in a gene of unknown function at 18p11.31 (BC040718), was associated with both disease status and onset age in our sample. However, this should be interpreted with caution because this SNP deviated from Hardy-Weinberg equilibrium in the control group, most likely because of low numbers of homozygous carriers of the rare allele (frequency of CC-genotype $=0.9 \%$ ). Moreover, it should be noted that this association would not survive Bonferroni correction for multiple testing. This SNP was only marginally associated with affection status in the original study sample and in the case-control samples of the GSK dataset showing nominal significance with the same risk allele [3].

Apart from a trend towards association between homozygous carriers for the opposite allele (A-allele of rs11159647) and onset age, we could not replicate the strongest finding of the original GWA study. Nor did we obtain an association for rs3826656 on chromosome 19. Several reasons can account for these discrepancies between our association findings and those reported in the original study, including chances of false positive or negative findings. Lack of power in our sample is unlikely since our sample size was twice as large as required to detect association with rs11159647 [3], and our power calculations showed sufficient power to detect modest effect sizes.

Due to the fact that our patient and control groups were not perfectly gender- or age-matched, we cannot exclude the possibility that some control individuals might still develop AD later in life. Nonetheless, considering that this will increase the chance of falsenegative findings rather than false-positive findings, the association signal we found with rs179943 may have been underestimated. In addition, the logistic regression analyses were adjusted for gender and age.

To further test whether our results might have been biased by the younger control group, we calculated genetic association after removing from the analysis all control individuals aged 50 years or less $(n=169)$. The remaining control group comprised 483 individuals with a mean age at inclusion of $70.4 \pm 10.0$ years. The association with rs 179943 remained significant, with a comparable OR as we had calculated in the total control population (CT genotype; $\mathrm{OR}=0.64,95 \% \mathrm{CI}=0.45-$ 0.92 , nominal $p=0.015$ ), lending extra credibility towards our findings. A similar finding was obtained for $\mathrm{rs} 2049161$ (CC genotype; OR $=2.80,95 \% \mathrm{CI}=$ 1.09-8.12, nominal $p=0.033$ ).

No other GWA studies on AD reported a direct association for one of the 4 SNPs under study [16-20]. Differences in study design may explain part of this lack of replication. For example, all other GWAs used population-based rather than family-based samples, and none used a multivariate analysis of AD risk and onset age. One study followed a DNA-pooling strategy which may have affected accuracy of genotype frequency estimates though errors in predicted frequencies were reported to be low [18]. One other study was limited to putative functional SNPs [16] and would therefore have missed all SNPs that were studied here. However, as most replication studies mainly focus on those SNPs that are genome-wide significant or surpass certain criteria for follow-up (e.g., a predefined number of most significant ('top') SNPs), the possibility exists that these 4 SNPs are still associated at a lower significance levels or that other SNPs in LD with those regions are associated. For example, two GWA studies, including one large international collaborative 
study, found numerous hits in a $2 \mathrm{Mb}$ region surrounding rs11159647 on chromosome 14 [17,21]. These SNPs are all positioned in predicted genes for which the biological interpretation remains unclear. Of interest, Beecham and colleagues [19] reported an association with rs 1402627 (p-value 4.42E-05), positioned at $6 \mathrm{~kb}$ from rs2049161 in the same cDNA BC040718 at 18 p11.31 [3], and this was the same SNP for which we found tentative evidence of association. Furthermore, Harold et al. [21] found an association with rs16879127 in $A P O E \& 4$ positive individuals positioned at $2 \mathrm{~kb} \mathrm{5}$, of the ATXN1 gene, further underscoring a possible role for this gene in $\mathrm{AD}$. Of note is that, although our patient/control sample was included in the latter GWA study, they were only used at stage 2 for replicating the genome-wide significant hits obtained at CLU and PICALM and not for the genome-wide genotyping.

It remains unclear at this stage whether the associations with opposite alleles at the same marker locus should be considered as evidence against a genuine association, or whether they are merely the result from minor population differences in LD structure, allele frequencies, and gene or environment interactions, particularly in light of the small effect sizes observed. However, given that our study population was of European ancestry, like the vast majority of samples used in the original report, this seems less plausible. But, it should be noted that, even in populations of European ancestry, allele frequencies can differ substantially, as seen, e.g., for rs11159647 when comparing genotype frequencies in our Belgian population with those of Utah residents with Northern and Western European ancestry from the CEPH collection of the International HapMap Project (http://www.hapmap.org/). Interpreting these effects in meta-analyses will be difficult and requires further investigation of the locus. A detailed comparison with the data of other GWA studies will permit to delineate chromosomal regions that should be targeted for fine-mapping efforts. Lastly, perhaps the original family-based study was enriched for less frequent alleles that we were unable to detect in our study population. Notwithstanding these difficulties, which are inherent to studies of complex diseases and traits, we found independent evidence of association for at least one SNP (rs179943 at chr6p22.3) and a tentative evidence for rs2049161 (at 18p11.31). Although technically, association with the opposite allele in our sample cannot be considered a direct replication of the original finding, the fact that we did find evidence of association at rs179943 suggests that a more in-depth exploration of this chromosomal region is warranted.
If our association signals point to genuine risk factors, they are unlikely to explain a large proportion of the variance, but nevertheless they might uncover important pathomechanisms involved in AD and onset of disease.

\section{ACKNOWLEDGMENTS}

We are grateful to the participants of this study for their cooperation. We further acknowledge the contribution of personnel of the VIB Genetic Service Facility (http://www.vibgeneticservicefacility.be/), the Biobank of the Institute Born-Bunge, and the department of Neurology at the University Hospitals of Leuven. This work was in part supported by the Special Research Fund of the University of Antwerp, the Fund for Scientific Research-Flanders (FWO-V); the Foundation for Alzheimer Research (SAO/FRMA), the Interuniversity Attraction Poles (IAP) program P6/43 of the Belgian Federal Science Policy Office, the Antwerp Medical Research Foundation and Neurosearch, and a Methusalem Excellence Grant of the Flemish Government, Belgium. K.S. is a postdoctoral fellow and K.B. and N.B. are PhD fellows of the FWO-V.

Authors' disclosures available online (http://www.jalz.com/disclosures/view.php?id=180).

\section{REFERENCES}

[1] Gatz M, Reynolds CA, Fratiglioni L, Johansson B, Mortimer JA, Berg S, Fiske A, Pedersen NL (2006) Role of genes and environments for explaining Alzheimer disease. Arch Gen Psychiatry 63, 168-174.

[2] Hindorff LA, Sethupathy P, Junkins HA, Ramos EM, Mehta JP, Collins FS, Manolio TA (2009) Potential etiologic and functional implications of genome-wide association loci for human diseases and traits. Proc Natl Acad Sci USA 106, 93629367.

[3] Ionita-Laza I, McQueen MB, Laird NM, Lange C (2007) Genomewide weighted hypothesis testing in family-based association studies, with an application to a $100 \mathrm{~K}$ scan. Am J Hum Genet 81, 607-614.

[4] Bertram L, Lange C, Mullin K, Parkinson M, Hsiao M, Hogan MF, Schjeide BM, Hooli B, Divito J, Ionita I, Jiang H, Laird N, Moscarillo T, Ohlsen KL, Elliott K, Wang X, Hu-Lince D, Ryder M, Murphy A, Wagner SL, Blacker D, Becker KD, Tanzi RE (2008) Genome-wide association analysis reveals putative Alzheimer's disease susceptibility loci in addition to APOE. Am J Hum Genet 83, 623-632.

[5] Li H, Wetten S, Li L, St Jean PL, Upmanyu R, Surh L, Hosford D, Barnes MR, Briley JD, Borrie M, Coletta N, Delisle R, Dhalla D, Ehm MG, Feldman HH, Fornazzari L, Gauthier S, Goodgame N, Guzman D, Hammond S, Hollingworth P, Hsiung GY, Johnson J, Kelly DD, Keren R, Kertesz A, King KS, 
Lovestone S, Loy-English I, Matthews PM, Owen MJ, Plumpton M, Pryse-Phillips W, Prinjha RK, Richardson JC, Saunders A, Slater AJ, George-Hyslop PH, Stinnett SW, Swartz JE, Taylor RL, Wherrett J, Williams J, Yarnall DP, Gibson RA, Irizarry MC, Middleton LT, Roses AD (2008) Candidate single-nucleotide polymorphisms from a genomewide association study of Alzheimer disease. Arch Neurol 65, 45-53.

[6] Reiman EM, Webster JA, Myers AJ, Hardy J, Dunckley T, Zismann VL, Joshipura KD, Pearson JV, Hu-Lince D, Huentelman MJ, Craig DW, Coon KD, Liang WS, Herbert RH, Beach T, Rohrer KC, Zhao AS, Leung D, Bryden L, Marlowe L, Kaleem M, Mastroeni D, Grover A, Heward CB, Ravid R, Rogers J, Hutton ML, Melquist S, Petersen RC, Alexander GE, Caselli RJ, Kukull W, Papassotiropoulos A, Stephan DA (2007) GAB2 alleles modify Alzheimer's risk in APOE epsilon4 carriers. Neuron 54, 713-720.

[7] Engelborghs S, Dermaut B, Goeman J, Saerens J, Marien P, Pickut BA, Van den BM, Serneels S, Cruts M, Van Broeckhoven C, De Deyn PP (2003) Prospective Belgian study of neurodegenerative and vascular dementia: APOE genotype effects. J Neurol Neurosurg Psychiatry 74, 1148-1151.

[8] Engelborghs S, Dermaut B, Marien P, Symons A, Vloeberghs E, Maertens K, Somers N, Goeman J, Rademakers R, Van den BM, Pickut B, Cruts M, Van Broeckhoven C, De Deyn PP (2006) Dose dependent effect of APOE epsilon4 on behavioral symptoms in frontal lobe dementia. Neurobiol Aging 27, 285292.

[9] McKhann G, Drachman D, Folstein M, Katzman R, Price D, Stadlan EM (1984) Clinical diagnosis of Alzheimer's disease: report of the NINCDS-ADRDA Work Group under the auspices of Department of Health and Human Services Task Force on Alzheimer's Disease. Neurology 34, 939-944.

[10] Folstein MF, Folstein SE, McHugh PR (1975) "Mini-mental state". A practical method for grading the cognitive state of patients for the clinician. J Psychiatr Res 12, 189-198.

[11] Brouwers N, Sleegers K, Engelborghs S, Bogaerts V, Serneels S, Kamali K, Corsmit E, De Leenheir E, Martin JJ, De Deyn PP, Van Broeckhoven C, Theuns J (2006) Genetic risk and transcriptional variability of amyloid precursor protein in Alzheimer's disease. Brain 129, 2984-2991.

[12] Purcell S, Cherny SS, Sham PC (2003) Genetic Power Calculator: design of linkage and association genetic mapping studies of complex traits. Bioinformatics 19, 149-150.

[13] Terwilliger J, Ott J (1994) Handbook of human genetic linkage. John Hopkins Press, Baltimore.

[14] Laird NM, Lange C (2006) Family-based designs in the age of large-scale gene-association studies. Nat Rev Genet 7, 385394.

[15] Schols L, Bauer P, Schmidt T, Schulte T, Riess O (2004) Autosomal dominant cerebellar ataxias: clinical features, genetics, and pathogenesis. Lancet Neurol 3, 291-304.

[16] Grupe A, Abraham R, Li Y, Rowland C, Hollingworth P, Morgan A, Jehu L, Segurado R, Stone D, Schadt E, Karnoub M, Nowotny P, Tacey K, Catanese J, Sninsky J, Brayne C,
Rubinsztein D, Gill M, Lawlor B, Lovestone S, Holmans P, O'Donovan M, Morris JC, Thal L, Goate A, Owen MJ, Williams J (2007) Evidence for novel susceptibility genes for late-onset Alzheimer's disease from a genome-wide association study of putative functional variants. Hum Mol Genet 16, 865-873.

[17] Carrasquillo MM, Zou F, Pankratz VS, Wilcox SL, Ma L, Walker LP, Younkin SG, Younkin CS, Younkin LH, Bisceglio GD, Ertekin-Taner N, Crook JE, Dickson DW, Petersen RC, Graff-Radford NR, Younkin SG (2009) Genetic variation in PCDH11X is associated with susceptibility to late-onset Alzheimer's disease. Nat Genet 41, 192-198.

[18] Abraham R, Moskvina V, Sims R, Hollingworth P, Morgan A, Georgieva L, Dowzell K, Cichon S, Hillmer AM, O’Donovan MC, Williams J, Owen MJ, Kirov G (2008) A genome-wide association study for late-onset Alzheimer's disease using DNA pooling. BMC Med Genomics 1, 44.

[19] Beecham GW, Martin ER, Li YJ, Slifer MA, Gilbert JR, Haines JL, Pericak-Vance MA (2009) Genome-wide association study implicates a chromosome 12 risk locus for late-onset Alzheimer disease. Am J Hum Genet 84, 35-43.

[20] Lambert JC, Heath S, Even G, Campion D, Sleegers K, Hiltunen M, Combarros O, Zelenika D, Bullido MJ, Tavernier B, Letenneur L, Bettens K, Berr C, Pasquier F, Fievet N, Barberger-Gateau P, Engelborghs S, De Deyn P, Mateo I, Franck A, Helisalmi S, Porcellini E, Hanon O, de Pancorbo MM, Lendon C, Dufouil C, Jaillard C, Leveillard T, Alvarez V, Bosco P, Mancuso M, Panza F, Nacmias B, Bossu P, Piccardi P, Annoni G, Seripa D, Galimberti D, Hannequin D, Licastro F, Soininen H, Ritchie K, Blanche H, Dartigues JF, Tzourio C, Gut I, Van Broeckhoven C, Alperovitch A, Lathrop M, Amouyel P (2009) Genome-wide association study identifies variants at CLU and CR1 associated with Alzheimer's disease. Nat Genet 41, 1094-1099.

[21] Harold D, Abraham R, Hollingworth P, Sims R, Gerrish A, Hamshere ML, Pahwa JS, Moskvina V, Dowzell K, Williams A, Jones N, Thomas C, Stretton A, Morgan AR, Lovestone S, Powell J, Proitsi P, Lupton MK, Brayne C, Rubinsztein DC, Gill M, Lawlor B, Lynch A, Morgan K, Brown KS, Passmore PA, Craig D, McGuinness B, Todd S, Holmes C, Mann D, Smith AD, Love S, Kehoe PG, Hardy J, Mead S, Fox N, Rossor M, Collinge J, Maier W, Jessen F, Schurmann B, van den Bussche H, Heuser I, Kornhuber J, Wiltfang J, Dichgans M, Frolich L, Hampel H, Hull M, Rujescu D, Goate AM, Kauwe JS, Cruchaga C, Nowotny P, Morris JC, Mayo K, Sleegers K, Bettens K, Engelborghs S, De Deyn PP, Van Broeckhoven C, Livingston G, Bass NJ, Gurling H, McQuillin A, Gwilliam R, Deloukas P, Al-Chalabi A, Shaw CE, Tsolaki M, Singleton AB, Guerreiro R, Muhleisen TW, Nothen MM, Moebus S, Jockel KH, Klopp N, Wichmann HE, Carrasquillo MM, Pankratz VS, Younkin SG, Holmans PA, O'Donovan M, Owen MJ, Williams J (2009) Genome-wide association study identifies variants at CLU and PICALM associated with Alzheimer's disease. Nat Genet 41, 1088-1093. 